\title{
NEW STRATEGY REQUIRED FOR DENTAL RESEARCH
}

An overhaul of the way dental research is organised is required in order to enhance excellence and ensure that it remains internationally competitive, according to a UK research summit for oral and dental researchers about the current state of dental research and its future.

Delegates from institutions across the UK highlighted a number of steps that must be taken to build on current successes, including closer collaboration with other researchers such as chemists and materials scientists, better engagement with funding bodies and the public, and refocusing research activity on quality rather than quantity.

The research summit, which was organised by Professor Paul Speight, President of the British Society for Oral and Dental Research (BSODR), was held at Sheffield University. It attracted 60 leading figures from dental research across the UK including representatives of every UK dental school, the Faculty of General Dental Practice, the Cochrane Oral Health Group and the Department of Health.
The speakers were Professor Stephen Holgate (Medical Research Council), Professor David Williams (President of the International Association of Dental Research), Professor Mike Curtis (Immediate Past President of BSODR) and Professor Jimmy Steele (Newcastle University).

The event was sponsored by the British Dental Association (BDA), BSDOR and the National Institute for Health Research. A full strategy with detailed proposals for next steps will now be developed by the BSDOR.

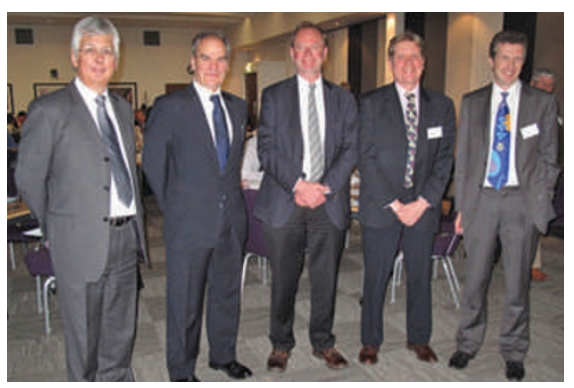

Paul Speight (far left) and the four speakers, David Williams, Stephen Holgate, Mike Curtis and Jimmy Steele (L-R)

\section{INCREASE IN CLINICAL ACADEMIC STAFFING LEVELS}

There has been a $2 \%$ increase in the number of clinical academics in UK dental schools during the 2008-09 academic year, to a total of 478 full-time equivalents (FTE), the highest number since 2000, according to data published by the Dental Schools Council.

The 2009 data reveal a return to total staffing levels higher than in 2000. However, this disguises a $21 \%$ decline (101 FTE) in the number of research active clinical academics - professors, senior lecturers and lecturers - in the same time period.

The dental schools are especially encouraged by the 12\% (15 FTE) increase in the number of lecturers between 2008 and 2009, and the evidence that younger clinical academics are being drawn from a more diverse population in terms of gender, age and ethnicity.

Despite this, there remain areas of concern. Women continue to be underrepresented at senior clinical academic grades, with just 10 of the 17 dental schools employing a female professor. In addition, as 55\% of clinical academics are aged over 46, compared with $51 \%$ in 2004 , the recent increase in lecturers alone may be insufficient to replace the expertise and leadership in clinical academia lost through retirement, and the low staffing levels in many dental specialties renders them especially vulnerable to change.

Professor William P. Saunders, Chair of the Dental Schools Council, said 'We are delighted by the recent increase in staffing levels in UK dental schools. However, we do anticipate the added pressures to the public purse over the coming years, and, as a community of dental schools, we look to work closely to protect and support the quality of teaching and research, as well as the contributions of clinical academics to the NHS and of clinicians to academia.'

The survey can be accessed online at www.dentalschoolscouncil.ac.uk/clinical_academic_staffing_survey.htm. 